\title{
Influência da colheita e períodos de armazenamento na qualidade sanitária de sementes de mamoneira
}

\author{
Sheila Fanan ${ }^{1,2^{*}}$, Priscila Fratin Medina ${ }^{3}$, Marcelo Bento Paes de Camargo $0^{3^{* *}}$, Margarida Fumiko Ito ${ }^{3 * *}$, Christina \\ Dudienas $^{3}$, Nilza Patrícia Ramos ${ }^{4}$, Rafael Galbieri ${ }^{1}$
}

${ }^{1}$ Instituto Mato-grossense do Algodão (IMA), Cx. P. 149, CEP 78850-000-Primavera do Leste-MT. ${ }^{2}$ Parte da dissertação de Mestrado do primeiro autor, Pós-Graduação em Agricultura Tropical e Subtropical/IAC, sheilafanan@imamt.com.br; ${ }^{3}$ Instituto Agronômico, Caixa Postal 28, 13001-970, Campinas, SP. ${ }^{4}$ EMBRAPA, Rod. SP 340, Km 127,5, Caixa Postal 69, CEP 13820-000 - Jaguariúna - SP. *Bolsista FAPESP; **Bolsista produtividade em Pesquisa do CNPq.

Autor Para correspondência: Sheila Fanan (sheilafanan@imamt.com.br)

Data de chegada: 23/06/2008. Aceito para publicação em: 16/02/2009

\section{RESUMO}

Fanan, S; Medina, P.F; Camargo, M.B.P; Ito, M.F; Dudienas, C; Ramos, N.P; Galbieri, R. Influência da colheita e períodos de armazenamento na qualidade sanitária de sementes de mamona. Summa Phytopathologica, v.35, n.3, p.202-209, 2009

As atuais preocupações quanto à escassez das reservas de petróleo e o agravamento do efeito estufa, pela emissão de $\mathrm{CO}_{2}$, levam a cultura da mamona a ser uma das fontes para energia renovável. Sabe-se que ao longo do ciclo da mamona são produzidos racemos de várias ordens, que se desenvolvem sob diferentes condições ambientais, podendo provocar variações na qualidade das sementes. Assim, objetivou-se avaliar a interferência da colheita e de cinco períodos de armazenamento na qualidade sanitária das sementes de mamona, cultivar IAC-2028. Para tanto, foram instalados os testes de germinação e sanidade, logo após a colheita e aos 3; 6; 9 e 12 meses de armazenamento em condições não controladas de temperatura e umidade relativa do ar. As avaliações foram feitas em esquema de parcela subdividida no tempo, onde as parcelas foram constituídas por cinco épocas trimestrais de avaliação e as subparcelas por 11 tratamentos. Os resultados sugerem que todos os racemos podem ser colhidos em uma única etapa, sem que ocorram perdas de qualidade das sementes.

Palavras-chave adicionais: Ricinus communis L., racemos, maturidade agronômica, fungos.

\section{ABSTRACT}

Fanan, S; Medina, P.F; Camargo, M.B.P; Ito, M.F; Dudienas, C; Ramos, N.P; Galbieri, R. Influence of harvesting time and storage periods in the sanitary quality of castor bean seeds. Summa Phytopathologica, v.35, n.3, p.202-209, 2009

The current concerns with the scarcity of oil reserves and the aggravation of the stove effect due to $\mathrm{CO}_{2}$ emission makes the castor bean oil one viable sources for renewable energy. During the crop growth racemes are produced in several orders that develop under different environment conditions, which can cause variations in quality of the seeds on the field and storage. The purpose of this work was to evaluate effect of harvest and five periods of storage on sanitary quality of seeds of castor bean cultivar IAC-2028. The evaluation of the quality of the seeds consisted of germination and sanitary test immediately after harvest, and at 3; 6;9 and 12 months of storage under uncontrolled conditions of air temperature and relative humidity. The results suggest that all the racemes can be harvested in a single harvesting time, without losses quality of the castor bean seeds.

Keywords: Ricinus communis L., racemes, agronomic maturity, fungi.

O óleo da mamona é o principal produto obtido após o processamento da matéria-prima, mamona em baga, sendo que $90 \%$ corresponde ao ácido ricinoléico. É esse ácido que confere ao óleo da mamona suas singulares propriedades para a fabricação de plásticos (nylon), cosméticos, tintas, lubrificantes. A cultura da mamona também tem chamado grande atenção devido ao incentivo à produção de biodiesel, o que exigirá grandes áreas de plantio para atender a demanda do mercado de combustíveis. No entanto, para que a ampliação da oferta dessa matéria-prima seja bem sucedida, é necessário desenvolver um conjunto de conhecimentos que permitam a obtenção de maior qualidade e conservação das sementes, para que essa cultura faça frente a outras opções como a soja, o amendoim e o girassol, cuja tecnologia de produção é mais aprimorada.
Os racemos não se desenvolvem ao mesmo tempo na planta, já que o florescimento da mamoneira é chamado botanicamente de simpodial, tipo em que o aparecimento da inflorescência dá-se seqüencialmente, a intervalos médios de 20 a 35 dias entre a emissão das inflorescências primárias, secundárias e terciárias, resultando na colheita parcelada, para as variedades deiscentes, à medida que os racemos vão amadurecendo, quando $2 / 3$ dos frutos estão secos (18).

Nesses casos, a colheita dos racemos da mamoneira é feita por várias etapas, periodicamente, no intuito de minimizar os efeitos da desuniformidade de maturação e maximizar a qualidade das sementes $(7,13)$.

O Instituto Agronômico (IAC) lançou em janeiro de 2007 uma nova cultivar de mamona, a IAC-2028, de frutos indeiscentes, elevado 
potencial produtivo, entre 1.500 a $2.800 \mathrm{Kg}$ /ha nas condições do Estado de São Paulo, ciclo precoce que varia de 150 a 180 dias até a colheita dos racemos terciários e quaternários e teor de óleo de $47 \%$.

Para cultivares de frutos indeiscentes, que não se abrem depois de secos, nem na planta e nem no terreiro, a colheita é realizada numa única etapa, quando todos os cachos da planta atingirem a maturidade fisiológica, o que possibilita a mecanização dessa operação (17).

No caso da colheita única, é importante que se avaliem possíveis perdas de qualidade das sementes, em função da sua permanência no campo, após a maturidade fisiológica ter sido atingida, já que de acordo com Soave \& Moraes (20), o atraso desnecessário na colheita das sementes maduras contribui para a sua deterioração, pois equivale a armazenar as sementes no campo, em condições bastante desfavoráveis, expondo-as por maior período de tempo a agentes patogênicos. Geralmente, o atraso na colheita de uma cultura está diretamente correlacionado com a maior quantidade de patógenos presentes nas sementes colhidas.

A associação de patógenos com sementes pode afetar, de forma severa, a qualidade fisiológica e sanitária dessas. Muitos desses fungos afetam a germinação das sementes e podem ser transmitidos à progênie resultante, podendo se estabelecer no campo de cultivo e causar prejuízo à qualidade das culturas $(4 ; 9 ; 16$ e 22). Os patógenos provocam danos indiretos nas plantações, devido à introdução rápida em novas áreas, onde anteriormente não existia a doença, comprometendo a qualidade dos grãos colhidos e armazenados (15).

De acordo com Carvalho \& Nakagawa (3) as sementes que apresentam menor potencial de armazenamento são aquelas que foram colhidas após o ponto de maturidade fisiológica, por já terem iniciado o processo de deterioração e as que foram atacadas por pragas e fungos no campo.

$\mathrm{Na}$ avaliação da qualidade sanitária das sementes de mamona, Massola \& Bedendo (12) e Savy Filho (18) consideraram que os fungos Fusarium oxysporum f. sp. ricini, causador da murcha de Fusarium e Alternaria ricini, causadora de manchas foliares, como os principais fungos patogênicos, no Estado de São Paulo, transmitidos por sementes.

Assim, o objetivo deste trabalho foi avaliar a influência da colheita e diversos períodos de armazenamento na qualidade sanitária de sementes de mamona, cultivar IAC-2028.

\section{MATERIAL E MÉTODOS}

\section{Experimento em campo:}

A instalação do experimento ocorreu no Centro Experimental Central do Instituto Agronômico -IAC, com os tratamentos: 1-CRP, 1-CRS, 1-CRT, 2-CR(P+S+T), 3-CRP(S), 3-CRS, 4-CU(P+S), 5CRP(T), 5-CRS(T), 5-CRT e 6-CU(P+S+T), com onze tratamentos definidos em seis parcelas distribuídas em cada um dos cinco blocos.

Foi utilizada a cultivar IAC-2028 de mamona (Ricinus communis L.), apta para colheita mecânica. A semeadura foi realizada em 19/12/ 2005, numa área de $3564 \mathrm{~m}^{2}$, sendo as parcelas constituídas por seis linhas de $11,0 \mathrm{~m}$ espaçadas de $1,8 \mathrm{~m}$, desprezando-se como bordadura $0,5 \mathrm{~m}$ das extremidades e duas linhas laterais, formando uma área útil de $72 \mathrm{~m}^{2}$.

Os tratamentos definidos da forma descrita na tabela 1 consistiram nas colheitas efetuadas de forma parcelada ou única, no período de 01 / 06 a 25/08/2006, quando o ponto de colheita foi atingido, ou seja, quando $2 / 3$ dos frutos nos racemos estavam secos. Esse ponto foi alcançado entre os dias 163 e 201 nos racemos primários, 163, 208 e 237 nos secundários e, 237 e 249 dias nos racemos terciários, após a semeadura. Não foi realizada secagem adicional após a colheita

Os dados médios de precipitação pluvial $(\mathrm{mm})$ e de temperatura $\left({ }^{\circ} \mathrm{C}\right)$, observados durante a condução da cultura, bem como as épocas em que os racemos primários, secundários e terciários atingiram o ponto de colheita estão na figura 1.

\section{Experimento em laboratório:}

Realizada a colheita, os racemos das plantas amostradas e correspondentes a cada tratamento foram conduzidos ao Laboratório de Análise de Sementes do Instituto Agronômico-IAC, localizado em Campinas-SP, onde foram realizados a remoção manual do pericarpo (casca) dos frutos, o armazenamento e a determinação da qualidade fisiológica das sementes. As sementes usadas para a avaliação da qualidade sanitária foram levadas ao Centro de Pesquisa e Desenvolvimento de Fitossanidade do Instituto Agronômico - IAC, para a realização dessa análise.

As sementes foram armazenadas em sacos de papel Kraft em condição ambiente, no Laboratório de Análise de Sementes do IAC por 12 meses. Foram realizadas avaliações trimestrais, tendo-se os dados de qualidade logo após a colheita (zero mês) e aos três, seis, nove e doze meses de armazenagem.

Tabela 1 - Descrição dos 11 tratamentos e dias da colheita dos racemos de mamona da cultivar IAC-2028.

\begin{tabular}{|c|c|c|}
\hline Tratamento & Descrição do tratamento & Dias da colheita \\
\hline $1-\mathrm{CRP}$ & Colheita parcelada do racemo primário & 163 e 201 \\
\hline $1-\mathrm{CRS}$ & Colheita parcelada do racemo secundário & 163,208 e 237 \\
\hline $1-\mathrm{CRT}$ & Colheita parcelada do racemo terciário & 237 e 249 \\
\hline $2-\mathrm{CR}(\mathrm{P}+\mathrm{S}+\mathrm{T})$ & $\begin{array}{l}\text { Colheita parcelada dos racemos primário, secundário, terciário e sementes misturadas após a colheita } \\
\text { do racemo terciário }\end{array}$ & $163,208,237$ e 249 \\
\hline 3-CRP(S) & Colheita parcelada do racemo primário quando o ponto de colheita do racemo secundário foi alcançado & 163,208 e 237 \\
\hline $3-\mathrm{CRS}$ & Colheita parcelada do racemo secundário & 163,208 e 237 \\
\hline 4-CU(P+S) & $\begin{array}{l}\text { Colheita única dos racemos primário e secundário, com sementes misturadas quando o ponto de } \\
\text { colheita do racemo secundário foi atingido }\end{array}$ & 163,208 e 237 \\
\hline $5-\mathrm{CRP}(\mathrm{T})$ & Colheita parcelada do racemo primário quando o ponto de colheita do racemo terciário foi atingido & 237 \\
\hline $5-\operatorname{CRS}(\mathrm{T})$ & Colheita parcelada do racemo secundário quando o ponto de colheita do racemo terciário foi atingido & 237 \\
\hline 5-CRT & Colheita parcelada do racemo terciário & 237 \\
\hline $6-\mathrm{CU}(\mathrm{P}+\mathrm{S}+\mathrm{T})$ & $\begin{array}{l}\text { Colheita única dos racemos primário, secundário e terciário, com sementes misturadas quando o } \\
\text { ponto de colheita do racemo terciário foi atingido }\end{array}$ & 237 e 249 \\
\hline
\end{tabular}


Tabela 2 - Média dos dados de germinação, referentes às porcentagens de plântulas normais (N) e sementes de mamona (cultivar IAC-2028) dormentes (D) e vivas (V), provenientes de diferentes tratamentos e armazenadas por 12 meses.

\begin{tabular}{|c|c|c|c|c|c|c|c|c|c|c|c|c|c|c|c|c|c|c|}
\hline \multirow[b]{3}{*}{ Tratamento ${ }^{*}$} & \multicolumn{18}{|c|}{ Meses de armazenamento } \\
\hline & \multicolumn{3}{|c|}{0} & \multicolumn{3}{|c|}{3} & \multicolumn{3}{|c|}{6} & \multicolumn{3}{|c|}{9} & \multicolumn{3}{|c|}{12} & \multicolumn{3}{|c|}{ Média } \\
\hline & $\mathrm{N}$ & $\mathrm{D}$ & $\mathrm{V}$ & $\mathrm{N}$ & $\mathrm{D}$ & $\mathrm{V}$ & $\mathrm{N}$ & $\mathrm{D}$ & $\mathrm{V}$ & $\mathrm{N}$ & $\mathrm{D}$ & $\mathrm{V}$ & $\mathrm{N}$ & $\mathrm{D}$ & $\mathrm{V}$ & $\mathrm{N}$ & $\mathrm{D}$ & $\mathrm{V}$ \\
\hline 1-CRP & 96 & 1 & 97 & 94 & 0 & 94 & 94 & 1 & 95 & 92 & 3 & 95 & 81 & 5 & 86 & $91 a^{(1)}$ & $2 a$ & $93 a$ \\
\hline 1-CRS & 94 & 2 & 96 & 93 & 2 & 95 & 94 & 1 & 95 & 91 & 3 & 94 & 89 & 3 & 92 & $92 \mathrm{a}$ & $2 \mathrm{a}$ & $94 a$ \\
\hline 1-CRT & 92 & 4 & 96 & 94 & 0 & 94 & 92 & 1 & 93 & 93 & 3 & 96 & 86 & 5 & 91 & $91 \mathrm{a}$ & $3 a$ & $94 a$ \\
\hline $2-\mathrm{CR}(\mathrm{P}+\mathrm{S}+\mathrm{T})$ & 92 & 2 & 94 & 98 & 0 & 98 & 92 & 0 & 92 & 88 & 8 & 96 & 81 & 8 & 89 & $90 \mathrm{a}$ & $3 a$ & $94 a$ \\
\hline 3-CRP(S) & 95 & 0 & 95 & 95 & 1 & 96 & 93 & 0 & 93 & 94 & 4 & 98 & 87 & 3 & 90 & $93 \mathrm{a}$ & $2 \mathrm{a}$ & $94 a$ \\
\hline 3-CRS & 96 & 0 & 96 & 96 & 0 & 96 & 95 & 1 & 96 & 94 & 2 & 96 & 85 & 0 & 85 & $93 a$ & la & $94 a$ \\
\hline 4-CU(P+S) & 92 & 1 & 93 & 95 & 1 & 96 & 91 & 1 & 92 & 96 & 2 & 98 & 85 & 2 & 87 & $92 a$ & la & $93 a$ \\
\hline 5-CRP(T) & 95 & 0 & 95 & 96 & 0 & 96 & 93 & 0 & 93 & 90 & 8 & 98 & 95 & 1 & 96 & $94 a$ & $2 \mathrm{a}$ & $96 a$ \\
\hline 5-CRS(T) & 98 & 0 & 98 & 96 & 0 & 96 & 97 & 0 & 97 & 93 & 5 & 98 & 92 & 1 & 93 & $95 \mathrm{a}$ & la & $96 a$ \\
\hline 5-CRT & 99 & 0 & 99 & 97 & 0 & 97 & 93 & 1 & 94 & 90 & 7 & 97 & 81 & 7 & 88 & $92 \mathrm{a}$ & $3 a$ & $95 \mathrm{a}$ \\
\hline 6-CU(P+S+T) & 96 & 0 & 96 & 97 & 1 & 98 & 92 & 0 & 92 & 93 & 4 & 97 & 87 & 4 & 91 & $93 \mathrm{a}$ & $2 \mathrm{a}$ & $95 a$ \\
\hline Média & $95 \mathrm{~A}^{(1)}$ & $1 \mathrm{~A}$ & $96 \mathrm{AB}$ & $95 \mathrm{~A}$ & $0.5 \mathrm{~A}$ & $96 \mathrm{AB}$ & $93 \mathrm{AB}$ & $0.5 \mathrm{~A}$ & 94BC & 92B & 4B & 97A & $86 \mathrm{C}$ & $3 \mathrm{~B}$ & $90 \mathrm{C}$ & & & \\
\hline CV (época) (\%) & 2,4 & 28,8 & 2,7 & & & & & & & & & & & & & & & \\
\hline CV (tratamento) $(\%)$ & 9,4 & 90,7 & 8,8 & & & & & & & & & & & & & & & \\
\hline
\end{tabular}

${ }^{1)}$ Médias seguidas de mesma letra, maiúscula na linha e minúscula na coluna não diferem entre si pelo teste de Tukey a 5\% de probabilidade. Dados transformados em arco seno "x/100. "Tabela 1.

Tabela 3 - Média dos dados obtidos no teste de germinação, referentes a porcentagem de sementes de mamona (cultivar IAC-2028), infectadas (I) e mortas (M), provenientes de diferentes tratamentos e armazenadas por 12 meses.

\begin{tabular}{|c|c|c|c|c|c|c|}
\hline \multirow[b]{2}{*}{ Tratamento } & \multicolumn{6}{|c|}{ Meses de armazenamento } \\
\hline & 0 & 3 & 6 & 9 & 12 & Média \\
\hline $1-\mathrm{CRS}$ & 48 & 45 & 6 & 6 & 4 & $22 \mathrm{a}$ \\
\hline 1-CRT & 50 & 45 & 5 & 8 & 4 & $22 \mathrm{a}$ \\
\hline 3-CRS & 49 & 45 & 10 & 4 & 4 & $22 \mathrm{a}$ \\
\hline 5-CRT & 47 & 41 & 14 & 15 & 4 & $24 \mathrm{ab}$ \\
\hline 4-CU(P+S) & 60 & 45 & 17 & 6 & 5 & $27 \mathrm{ab}$ \\
\hline 6-CU(P+S+T) & 51 & 41 & 25 & 13 & 10 & $28 \mathrm{ab}$ \\
\hline $2-\mathrm{CR}(\mathrm{P}+\mathrm{S}+\mathrm{T})$ & 57 & 47 & 14 & 17 & 11 & $29 \mathrm{abc}$ \\
\hline 3-CRP (S) & 55 & 48 & 23 & 18 & 13 & $31 \mathrm{abc}$ \\
\hline 5-CRS(T) & 62 & 61 & 24 & 25 & 8 & $36 \mathrm{bc}$ \\
\hline 1-CRP & 77 & 67 & 42 & 13 & 12 & $42 \mathrm{~cd}$ \\
\hline 5-CRP(T) & 64 & 57 & 60 & 52 & 50 & $57 \mathrm{~d}$ \\
\hline Média & $56 \mathrm{D}$ & $49 \mathrm{C}$ & $22 \mathrm{~B}$ & $16 \mathrm{~A}$ & $11 \mathrm{~A}$ & 30,9 \\
\hline CV(\%) (época) & 10,5 & & & & & \\
\hline $\mathrm{CV}(\%)$ (tratamento) & 34,9 & & & & & \\
\hline
\end{tabular}

À medida que as sementes completavam os períodos trimestrais de armazenamento em ambiente não controlado, foram aplicados os seguintes testes para a avaliação de qualidade das sementes: grau de umidade - realizado em estufa a $105^{\circ} \mathrm{C} \pm 3{ }^{\circ} \mathrm{C} / 24 \mathrm{~h}$, constituído de duas subamostras em cada uma das cinco repetições com cerca de 6 g para cada tratamento, de acordo com Brasil (2); germinação - cinco repetições de 50 sementes cada repetição foram distribuídas em rolo de papel tipo Germitest, umedecido com quantidade equivalente a 2,5 vezes a massa do substrato seco, e colocadas para germinar em temperatura alternada de $20^{\circ} \mathrm{C}-30^{\circ} \mathrm{C}$ e luz constante. As contagens foram realizadas aos sete e 14 dias após a semeadura e as avaliações efetuadas segundo os critérios estabelecidos pelas Regras para Análise de Sementes - Brasil (2); teste de tetrazólio - utilizou-se a metodologia descrita por Brasil
(2) e por Delouche et al. (5), onde as sementes individuais, que permaneceram dormentes ou intumescidas no final do teste de germinação foram cortadas longitudinalmente através do seu eixo embrionário e mantidas as duas extremidades da carúncula unidas para a avaliação. Após os cortes, as sementes foram colocadas em recipientes plásticos cobertas com solução do sal de tetrazólio $(0,5 \%)$ e mantidas em câmara escura à $40{ }^{\circ} \mathrm{C}$ por 4 horas. Passado esse tempo, removeu-se a solução de tetrazólio e as sementes foram lavadas com água. Os tecidos internos das sementes foram analisados para a caracterização de sementes vivas e mortas; sanidade - por meio do método de incubação em papel de filtro sem congelamento Blotter test (11), usou-se 40 sementes por repetição, distribuídas em 4 placas de Petri com 10 sementes cada, o que totalizou 200 sementes por tratamento. As sementes, sem desinfestação 


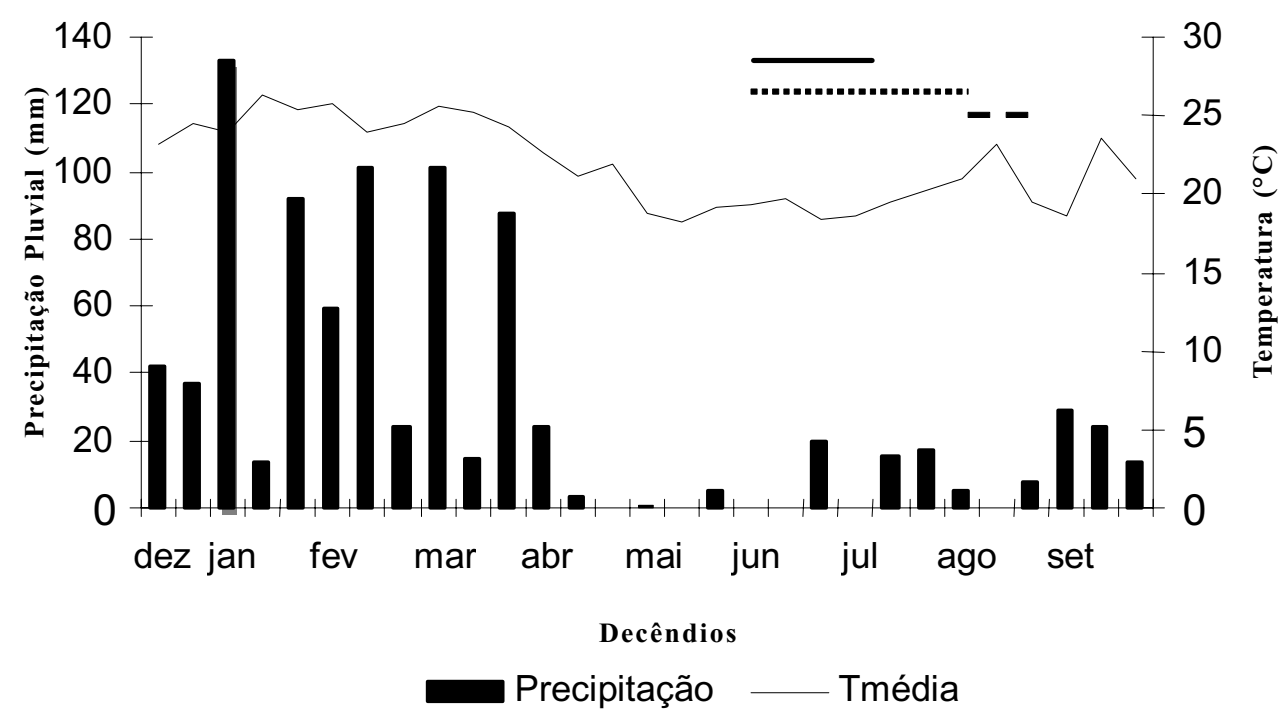

Figura 1 - Épocas em que os racemos primário ), secundário (......) e terciário ( ) de mamona, cultivar IAC-2028, atingiram o ponto de colheita; totais de precipitação e média de temperatura do ar, ao nível decendial, registradas entre o período de plantio e colheita, de dezembro/2005 a agosto/2006, em Campinas-SP.

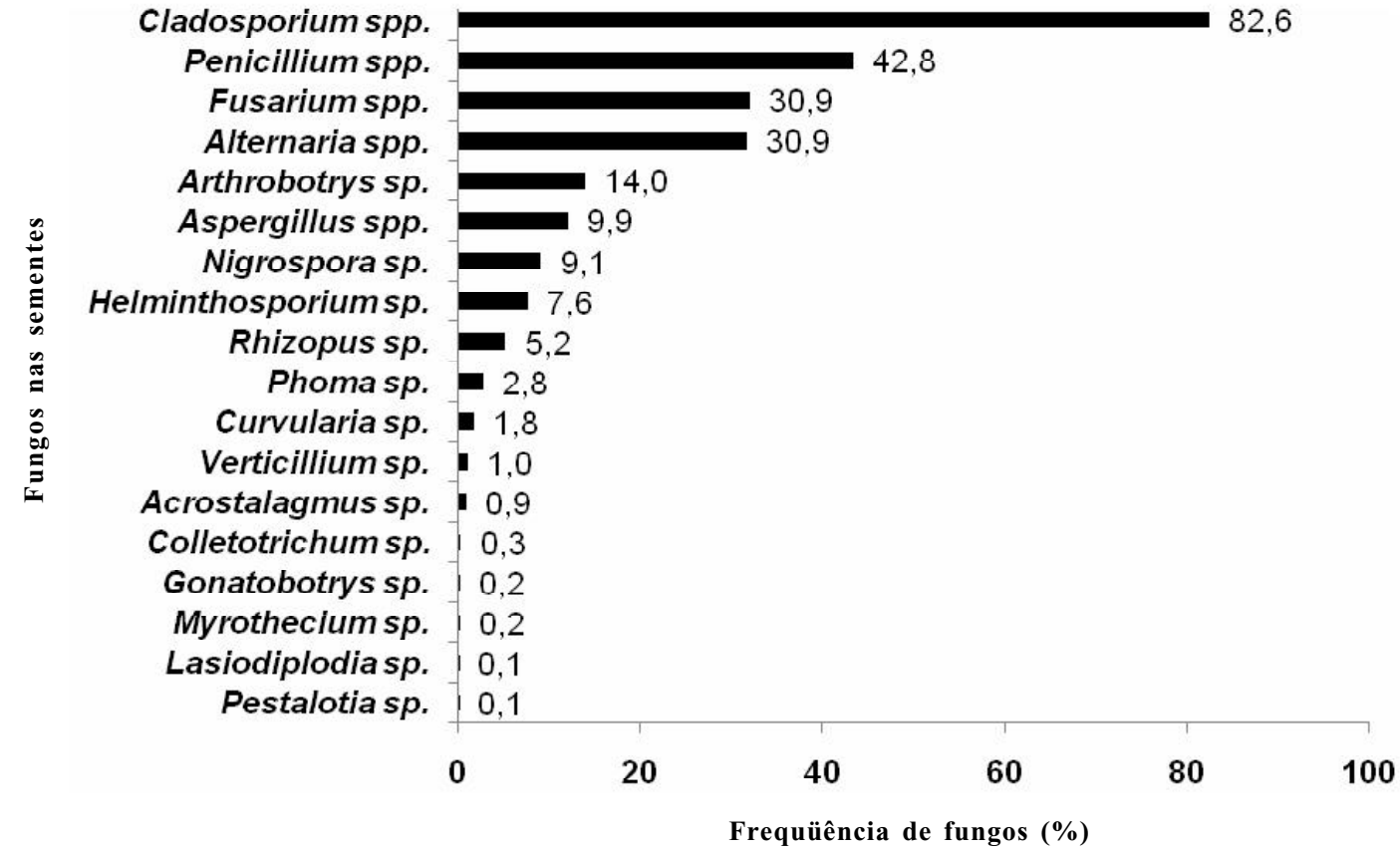

Figura 2 - Porcentagem média de fungos associados às sementes de mamona, cultivar IAC-2028, nos 11 tratamentos e armazenadas por 12 meses.

superficial, foram distribuídas sobre três folhas de papel de filtro devidamente umedecidas com água destilada esterilizada. As placas foram incubadas à luz fluorescente, com fotoperíodo de 12 horas, a temperatura de $20^{\circ} \mathrm{C} \pm 2{ }^{\circ} \mathrm{C}$, por 8 dias. No final do período de incubação foi feita a avaliação qualitativa e quantitativa dos fungos associados às sementes, utilizando-se microscópio estereoscópico.

A análise estatística foi realizada utilizando-se parcelas subdivididas no tempo, que foram constituídas por cinco épocas trimestrais de avaliação e as sub-parcelas de 11 tratamentos. Os dados obtidos em cada teste foram analisados pela análise de variância, com comparação de médias pelo teste de Tukey a 5\% de probabilidade, empregando-se o Programa de Análise estatística SANEST (24).

\section{RESULTADOS E DISCUSSÃO}

Os valores médios de germinação referentes às porcentagens de plântulas normais, sementes dormentes, vivas, infectadas e mortas de sementes armazenadas em temperatura ambiente, encontram-se nas Tabelas 2 e 3. 
Pelos padrões nacionais para produção e comercialização de sementes de mamona (1), a porcentagem de germinação mínima deve ser de $80 \%$ para sementes básicas e de $85 \%$ para as sementes certificadas de primeira e de segunda geração $(\mathrm{C} 1$ e $\mathrm{C} 2)$ e para as não certificadas de primeira e segunda geração (S1 e S2). Verificou-se que esses níveis foram superados em todas as épocas de armazenamento para todos os tratamentos. A partir dos seis meses, no entanto, constatou-se uma queda na porcentagem média de germinação das sementes, que não afetou consideravelmente sua qualidade, já que a germinação permaneceu acima de $85 \%$, mesmo quando armazenadas por 12 meses.

A porcentagem de sementes vivas, representadas pela soma das plântulas normais com as sementes dormentes, sendo estas detectadas pelo teste de tetrazólio, foi superior a $90 \%$ para todos os períodos de armazenamento, o que indicou que as condições de armazenagem não foram prejudiciais à qualidade das sementes.

De acordo com Marcos Filho (10), a ação conjunta da temperatura e umidade relativa do ar durante o armazenamento determina a longevidade das sementes, pois altas umidades relativas e temperaturas aceleram o processo de deterioração de sementes ortodoxas como a mamona.

Neste trabalho verificou-se que durante o armazenamento das sementes a temperatura mínima média foi de $11,1^{\circ} \mathrm{C}$ e a máxima média foi de $31,9{ }^{\circ} \mathrm{C}$, correspondendo média a $21,5^{\circ} \mathrm{C}$; já os valores da umidade relativa média do ar variaram de $26,8 \%$ a $100 \%$, sendo a média de $63,4 \%$. Apesar dessas variações, o grau de umidade das sementes ficou em torno de $6 \%$ em todos os períodos de armazenagem.

A alta porcentagem inicial de germinação das sementes, de $92 \%$ a até $99 \%$, resultou da influência dos elementos climáticos durante a colheita dos racemos. O teor médio de água de 6,5\% detectada nas sementes logo após a colheita, ocorreu em função da precipitação pluvial baixa, em torno de $67 \mathrm{~mm}$ que, juntamente com a temperatura média de $20^{\circ} \mathrm{C}$, foram favoráveis à conservação das sementes após a colheita (Figura 1).

Com isso, houve uma uniformidade na qualidade das sementes independentemente da época de colheita (Tabela 2), o que provavelmente não ocorreria se as condições ambientais tivessem sido adversas
Não houve diferença estatística entre os tratamentos quanto à porcentagem de sementes infectadas e mortas. No entanto, a Tabela 3 mostra que essas porcentagens foram maiores aos 12 meses de armazenamento, apesar da quantidade de sementes mortas ter sido praticamente insignificante.

Esse aumento na porcentagem de sementes infectadas, aos 12 meses de armazenamento, coincidiu com a redução da porcentagem de germinação, que indica a influência da incidência de fungos na qualidade das sementes.

Os fungos detectados nas sementes de mamona estão relacionados na Figura 2. Verificou-se, uma maior incidência do gênero Cladosporium spp. (82,6\%), seguido dos gêneros Penicillium spp. (42,8\%), Fusarium spp. e Alternaria spp. (30,9\%), Arthrobotrys spp. (14,0\%) e Aspergillus spp. (9,9\%).

A Tabela 4 mostra a incidência de Fusarium spp. nas sementes de mamona. $\mathrm{O}$ tratamento 5-CRP(T), cujos racemos permaneceram mais tempo no campo, apresentou a maior porcentagem média de sementes com a presença do fungo, enquanto que a menor porcentagem foi para as sementes dos tratamentos 1-CRS, 1-CRT e 3-CRS, em que as sementes foram colhidas assim que atingiram o ponto de colheita, de forma que um maior período de armazenamento da semente no campo resultou em maior incidência desse fungo, embora a temperatura média nesse período (Figura 1) tenha sido um pouco inferior às relatadas por Moshkin (14), entre $22{ }^{\circ} \mathrm{C}$ e $25{ }^{\circ} \mathrm{C}$ como as que proporcionam as condições ideais ao desenvolvimento do fungo e morte de plantas de variedades suscetíveis.

Apesar de o gênero Fusarium ter sido encontrado em 57\% das sementes do tratamento 5-CRP(T), não causou prejuízo para a germinação das sementes, como pode ser constatado com os resultados desse teste (Tabelas 2 e 3 ).

O mesmo ocorreu com as sementes dos tratamentos 1-CRS, 1CRT e 3-CRS onde a baixa incidência do Fusarium spp., de $22 \%$, não levou a um aumento na germinação, em relação aos outros tratamentos.

Apesar de o Fusarium spp. ter permanecido viável até o final do período de armazenamento, a sobrevivência foi baixa, partindo de incidência inicial de $56 \%$ e atingindo média final de $11 \%$.

Na Tabela 5 estão os dados de incidência de Alternaria spp. nas

Tabela 4 - Porcentagens de sementes de mamona, cultivar IAC-2028, com incidência de Fusarium spp., nos diferentes tratamentos, armazenadas por cinco períodos.

\begin{tabular}{|c|c|c|c|c|c|c|}
\hline \multirow[b]{2}{*}{ Tratamento } & \multicolumn{6}{|c|}{ Meses de armazenamento } \\
\hline & 0 & 3 & 6 & 9 & 12 & Média \\
\hline 1-CRS & 48 & 45 & 6 & 6 & 4 & $22 \mathrm{a}$ \\
\hline 1-CRT & 50 & 45 & 5 & 8 & 4 & $22 \mathrm{a}$ \\
\hline 3-CRS & 49 & 45 & 10 & 4 & 4 & $22 \mathrm{a}$ \\
\hline 5-CRT & 47 & 41 & 14 & 15 & 4 & $24 \mathrm{ab}$ \\
\hline 4-CU(P+S) & 60 & 45 & 17 & 6 & 5 & $27 \mathrm{ab}$ \\
\hline 6-CU $(\mathrm{P}+\mathrm{S}+\mathrm{T})$ & 51 & 41 & 25 & 13 & 10 & $28 \mathrm{ab}$ \\
\hline $2-\mathrm{CR}(\mathrm{P}+\mathrm{S}+\mathrm{T})$ & 57 & 47 & 14 & 17 & 11 & $29 \mathrm{abc}$ \\
\hline 3-CRP (S) & 55 & 48 & 23 & 18 & 13 & $31 \mathrm{abc}$ \\
\hline 5-CRS(T) & 62 & 61 & 24 & 25 & 8 & $36 \mathrm{bc}$ \\
\hline 1-CRP & 77 & 67 & 42 & 13 & 12 & $42 \mathrm{~cd}$ \\
\hline $5-\mathrm{CRP}(\mathrm{T})$ & 64 & 57 & 60 & 52 & 50 & $57 \mathrm{~d}$ \\
\hline Média & $56 \mathrm{D}$ & $49 \mathrm{C}$ & $22 \mathrm{~B}$ & $16 \mathrm{~A}$ & $11 \mathrm{~A}$ & 30,9 \\
\hline CV(\%) (época) & 10,5 & & & & & \\
\hline $\mathrm{CV}(\%)$ (tratamento) & 34,9 & & & & & \\
\hline
\end{tabular}


Tabela 5 - Porcentagens de sementes de mamona, cultivar IAC-2028, com incidência de Alternaria spp., nos diferentes tratamentos, armazenadas por cinco períodos.

\begin{tabular}{|c|c|c|c|c|c|c|}
\hline \multirow[b]{2}{*}{ Tratamento } & \multicolumn{6}{|c|}{ Meses de armazenamento } \\
\hline & 0 & 3 & 6 & 9 & 12 & Média \\
\hline $2-\mathrm{CR}(\mathrm{P}+\mathrm{S}+\mathrm{T})$ & 48 & 30 & 14 & 8 & 7 & $21 \mathrm{a}^{(1)}$ \\
\hline $1-\mathrm{CRP}$ & 42 & 30 & 36 & 9 & 5 & $24 \mathrm{a}$ \\
\hline 1-CRS & 62 & 40 & 23 & 4 & 3 & $26 \mathrm{ab}$ \\
\hline 3-CRS & 75 & 31 & 18 & 5 & 2 & $26 \mathrm{ab}$ \\
\hline 4-CU(P+S) & 53 & 47 & 30 & 7 & 1 & $28 \mathrm{ab}$ \\
\hline 3-CRP(S) & 60 & 50 & 34 & 8 & 5 & $31 \mathrm{abc}$ \\
\hline 5-CRT & 63 & 54 & 22 & 10 & 8 & $31 \mathrm{abc}$ \\
\hline $1-\mathrm{CRT}$ & 64 & 62 & 25 & 5 & 4 & $32 a b c$ \\
\hline $6-\mathrm{CU}(\mathrm{P}+\mathrm{S}+\mathrm{T})$ & 64 & 58 & 32 & 12 & 5 & $34 \mathrm{abc}$ \\
\hline $5-\mathrm{CRS}(\mathrm{T})$ & 81 & 73 & 28 & 17 & 11 & $42 \mathrm{c}$ \\
\hline 5-CRP(T) & 63 & 63 & 36 & 36 & 26 & $45 \mathrm{c}$ \\
\hline Média & $61 \mathrm{D}^{(1)}$ & $49 \mathrm{C}$ & $27 \mathrm{~B}$ & $11 \mathrm{~A}$ & $7 \mathrm{~A}$ & 30,9 \\
\hline CV(\%) (época) & 7,7 & & & & & \\
\hline $\mathrm{CV}(\%)$ (tratamento) & 29,6 & & & & & \\
\hline
\end{tabular}

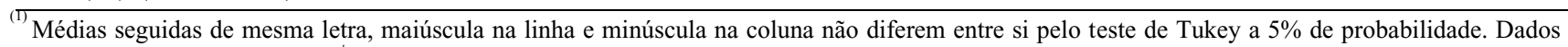
transformados em arco seno $\sqrt{\mathrm{x}} / 100$.

Tabela 6 - Porcentagens de sementes de mamona, cultivar IAC-2028, com incidência de Aspergillus spp., nos diferentes tratamentos, armazenadas por cinco períodos.

\begin{tabular}{|c|c|c|c|c|c|c|}
\hline \multirow[b]{2}{*}{ Tratamento } & \multicolumn{6}{|c|}{ Meses de armazenamento } \\
\hline & 0 & 3 & 6 & 9 & 12 & Média \\
\hline 5-CRP(T) & 0 & 0 & 1 & 1 & 1 & $1 \mathrm{a}^{(1)}$ \\
\hline $5-\mathrm{CRS}(\mathrm{T})$ & 0 & 0 & 2 & 3 & 4 & $2 \mathrm{ab}$ \\
\hline $6-\mathrm{CU}(\mathrm{P}+\mathrm{S}+\mathrm{T})$ & 0 & 0 & 4 & 6 & 1 & $2 \mathrm{ab}$ \\
\hline $3-\mathrm{CRP}(\mathrm{S})$ & 0 & 0 & 5 & 18 & 7 & $6 \mathrm{ab}$ \\
\hline $1-\mathrm{CRT}$ & 0 & 3 & 9 & 15 & 8 & $7 \mathrm{ab}$ \\
\hline $1-\mathrm{CRS}$ & 1 & 0 & 9 & 24 & 15 & $10 \mathrm{bc}$ \\
\hline 4-CU(P+S) & 0 & 5 & 10 & 19 & 16 & $10 \mathrm{bc}$ \\
\hline 3-CRS & 0 & 2 & 10 & 23 & 24 & $12 \mathrm{bc}$ \\
\hline 5-CRT & 1 & 5 & 9 & 28 & 17 & $12 \mathrm{bc}$ \\
\hline $2-\mathrm{CR}(\mathrm{P}+\mathrm{S}+\mathrm{T})$ & 6 & 9 & 31 & 43 & 25 & $23 \mathrm{c}$ \\
\hline $1-\mathrm{CRP}$ & 4 & 7 & 25 & 68 & 18 & $24 \mathrm{c}$ \\
\hline Média & $1 \mathrm{~A}^{(1)}$ & $3 \mathrm{AB}$ & $10 \mathrm{BC}$ & $22 \mathrm{C}$ & $12 \mathrm{C}$ & 9,9 \\
\hline CV(\%) (época) & 35,1 & & & & & \\
\hline $\mathrm{CV}(\%)$ (tratamento) & 91,4 & & & & & \\
\hline
\end{tabular}

\footnotetext{
${ }^{(1)}$ Médias seguidas de mesma letra, maiúscula na linha e minúscula na coluna não diferem entre si pelo teste de Tukey a $5 \%$ de probabilidade. Dados transformados em arco seno $\sqrt{\mathrm{x}} / 100$.
}

sementes. O tratamento 5-CRP(T) também apresentou maior porcentagem de sementes com a presença desse patógeno, ou seja, de $45 \%$.

O gênero Alternaria permaneceu viável até o final do período de armazenamento; no entanto, apresentou sobrevivência ainda mais baixa do que a do Fusarium spp., obsevando-se incidência inicial de $61 \% \mathrm{e}$ final de 7\%. Tanaka (21) observou taxas muito baixas de sobrevivência de Fusarium moniliforme, ou seja, 2\% ao final de 12 meses de armazenamento, em sementes de milho.

Mais recentemente, Silva et al. (19) também verificaram redução na incidência dos gêneros Fusarium e Alternaria em sementes de paineira, de $13 \%$ e $5 \%$ respectivamente, ao final de 4 meses de armazenamento.
Durante os períodos de armazenamento, a umidade relativa do ar foi, em média, de $63,4 \%$, valor este abaixo da umidade requerida pelos fungos de campo, como Fusarium spp. e Alternaria spp., para se desenvolverem, que deve atingir, pelo menos, 90\% (Dhingra, 6).

Apesar da alta incidência inicial dos gêneros Fusarium e Alternaria, ou seja, acima de $55 \%$ nas sementes, a porcentagem de geminação atingiu $95 \%$, e o início da sua redução coincidiu com o início da queda desses fungos de campo, aos 6 meses de armazenamento.

As Tabelas 6 e 7 mostram a incidência dos gêneros Aspergillus e Penicillium, respectivamente, nas sementes de mamona. No Tratamento 1-CRP, as sementes apresentaram maior porcentagem média com a presença desses fungos de armazenamento, com incidência de $24 \%$ do 
Tabela 7 - Porcentagens de sementes de mamona, cultivar IAC-2028, com incidência de Penicillium spp., nos diferentes tratamentos, armazenadas por cinco períodos.

\begin{tabular}{|c|c|c|c|c|c|c|}
\hline \multirow[b]{2}{*}{ Tratamento } & \multicolumn{6}{|c|}{ Meses de armazenamento } \\
\hline & 0 & 3 & 6 & 9 & 12 & Média \\
\hline 5-CRP(T) & 0 & 6 & 21 & 15 & 19 & $12 a^{(1)}$ \\
\hline 5-CRS(T) & 2 & 10 & 41 & 34 & 42 & $26 \mathrm{ab}$ \\
\hline 6-CU(P+S+T) & 0 & 17 & 31 & 58 & 43 & $30 \mathrm{abc}$ \\
\hline 3-CRP(S) & 4 & 12 & 50 & 61 & 49 & 35 bcd \\
\hline 4-CU(P+S) & 9 & 20 & 53 & 67 & 61 & 42 bcde \\
\hline 5-CRT & 15 & 36 & 64 & 57 & 61 & $47 \mathrm{cdef}$ \\
\hline 1-CRT & 9 & 19 & 75 & 72 & 72 & 49 def \\
\hline 3-CRS & 11 & 23 & 75 & 77 & 74 & $52 \mathrm{def}$ \\
\hline 1-CRS & 16 & 18 & 84 & 80 & 78 & 55 ef \\
\hline $2-\mathrm{CU}(\mathrm{P}+\mathrm{S}+\mathrm{T})$ & 24 & 18 & 86 & 82 & 87 & 59 ef \\
\hline $1-\mathrm{CRP}$ & 28 & 56 & 68 & 87 & 75 & $63 \mathrm{f}$ \\
\hline Média & $11 \mathrm{~A}^{(1)}$ & $21 \mathrm{~A}$ & $59 \mathrm{~B}$ & $63 \mathrm{~B}$ & $60 \mathrm{~B}$ & 42,8 \\
\hline CV(\%) (época) & 13,8 & & & & & \\
\hline $\mathrm{CV}(\%)$ (tratamento) & 34,6 & & & & & \\
\hline
\end{tabular}

Aspergillus spp. e 63\% com o Penicillium spp., o que indica que a colheita no momento certo do racemo primário não proporcionou uma menor incidência desses gêneros de fungos nas sementes de mamona.

Da mesma forma, a colheita atrasada do racemo primário no tratamento 5-CRP(T) que apresentou a menor incidência de Aspergillus spp., com $1 \%$ nas sementes e de Penicillium spp., com $12 \%$, coincidiu com a alta qualidade fisiológica das sementes deste tratamento (Tabela 2).

Durante o armazenamento, houve aumento na incidência dos gêneros Aspergillus e Penicillium nas sementes de todos os tratamentos até os nove meses, e queda, porém não significativa, no último período de armazenagem. Silva et al. (19) também observaram um aumento da incidência desses fungos com o aumento dos períodos de armazenamento.

$\mathrm{O}$ aumento dos fungos de armazenamento foi significativo a partir dos seis meses de armazenagem, principalmente para o gênero Penicillium, coincididindo com o aumento significativo das sementes infectadas e detectadas no teste de germinação, que apareceram em todos os tratamentos avaliados, e com o início da redução na porcentagem de germinação das sementes. No entanto, somente aos 12 meses de armazenamento a incidência dos fungos de armazenagem

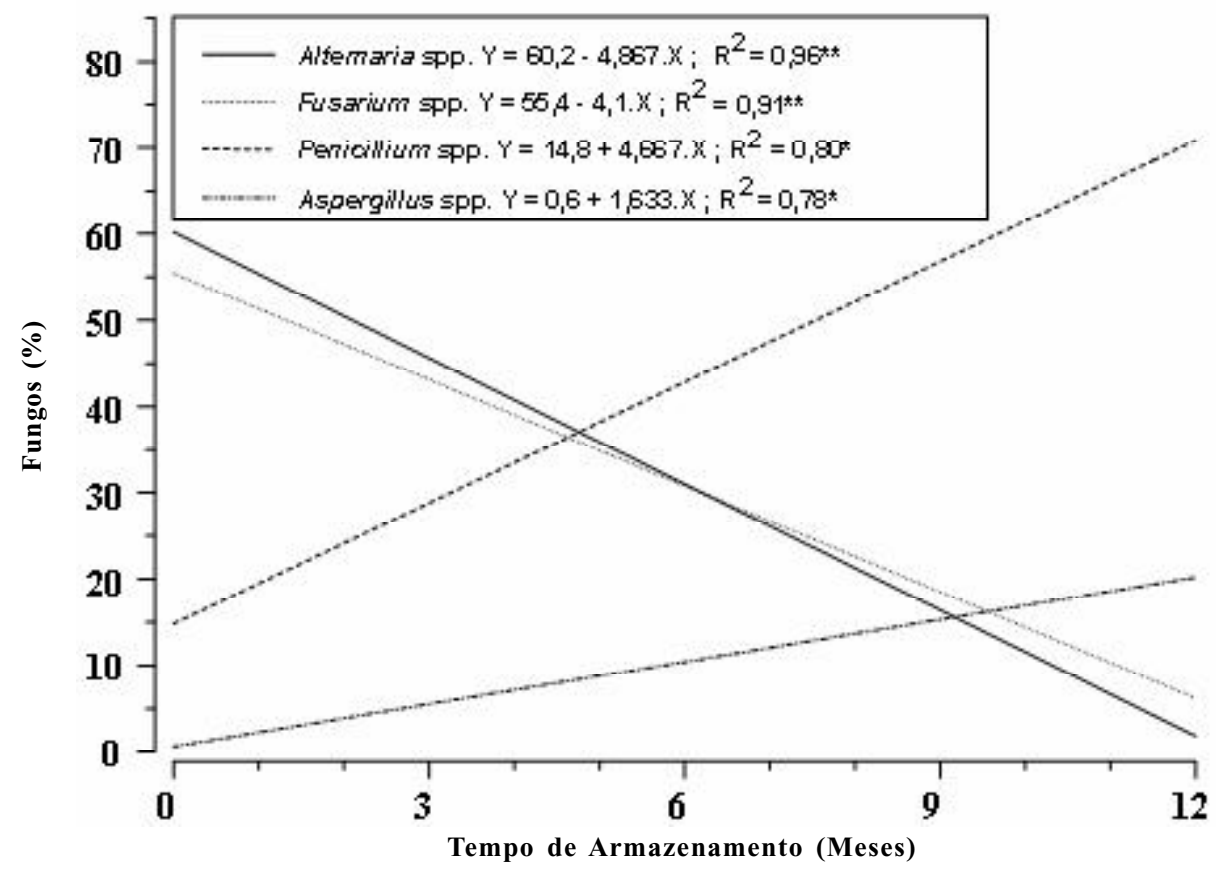

Figura 3 - Sobrevivência média de gêneros de fungos em sementes de mamona, cultivar IAC-2028, nos 11 tratamentos, em função do tempo de armazenamento. 
refletiu numa maior queda da porcentagem de germinação ( $86 \%)$ e de sementes vivas (90\%), em comparação com a qualidade inicial das sementes, de $95 \%$ e $96 \%$ respectivamente, e em um aumento significativo de sementes infectadas e mortas (Tabela 3 ).

Esse aumento da incidência de Penicillium spp. e Aspergillus spp. durante o armazenamento pode ser explicado pela afirmação de Dhingra (6) de que a temperatura ótima para o crescimento da maioria dos fungos de armazenamento está situada entre $28{ }^{\circ} \mathrm{C}$ a $35^{\circ} \mathrm{C}$, o que favorece a infecção das sementes armazenadas e o desenvolvimento, mesmo com umidade relativa de até $70 \%$; esse valor foi próximo ao valor médio $(63,4 \%)$ observado no armazenamento das sementes.

No entanto, as sementes apresentaram teores de umidades baixas e uniformes ao longo dos períodos de armazenagem. Dhingra (6) acrescentou que estando as sementes infectadas por fungos de armazenamento, o crescimento desses patógenos continuam mesmo para temperaturas e umidades inferiores às necessárias para que ocorra invasão destes em sementes sadias.

As sementes recém colhidas, ou seja, ao zero mês de armazenamento, já apresentavam a incidência de fungos de armazenamento, com valores de $1 \%$, em todos os tratamentos avaliados, para o gênero Aspergillus e de 11\% para o Penicillium spp.

A ocorrência desses fungos de armazenamento, em baixas porcentagens, em torno de $1 \%$, em sementes que ainda estavam no campo também foi relatada por Kennedy (8) e Wetzel (23), contrariando as informações de Dhingra (6), que negou esta possibilidade.

As análises de regressão constataram o efeito do período de 12 meses de armazenamento das sementes de mamona sobre a sobrevivência dos gêneros Fusarium, Alternaria, Aspergillus e Penicillium, verificando-se modelo linear decrescente para os dois primeiros casos e crescente para os demais (Figura 3), confirmando as informações encontradas na literatura $(19,21)$, de que os fungos de campo (Fusarium e Alternaria) decrescem com o tempo de armazenamento enquanto que os de armazenamento aumentam se expostos a condições favoráveis ao seu desenvolvimento.

As condições nas quais as sementes foram mantidas no campo durante as fases de colheita no ano de 2006, juntamente com a manutenção do baixo teor de água das sementes durante os 12 meses de armazenamento, são fatores que podem ter contribuído para a preservação da qualidade das sementes no campo e no armazém.

\section{AGRADECIMENTOS}

Os autores agradecem à FAPESP pela concessão de bolsa de Pósgraduação para Sheila Fanan e suporte financeiro nesta pesquisa, e ao $\mathrm{CNPq}$ pela bolsa em Produtividade Científica para Marcelo Bento Paes de Camargo e Margarida Fumiko Ito.

\section{REFERÊNCIAS BIBLIOGRÁFICAS}

1. Brasil. Padrões para produção e comercialização de sementes de mamona. Diário Oficial da União. Brasília, DF, n: 243, 2005 seção 1, p. 21-22.

2. Brasil. Ministério da Agricultura e da Reforma Agrária. Regras para análise de sementes. Brasília, 1992. 365p.

3. Carvalho, N.M.; Nakagawa, J. Sementes: ciência, tecnologia e produção. 4. ed. Jaboticabal: Funep, 2000. 588p.

4. Castellani, E.E.; Silva, A.; Barreto, M.; Aguiar, I.B. Influência do tratamento químico na população de fungos e na germinação de sementes de Bauhinia variegata L. var variegata. Revista Brasileira de Sementes, Brasília, v.18, n.1, p.41-44, 1996.
5. Delouche, J.C.; Still, T.W.; Raspet, M.; Lienhard, M. O teste de tetrazólio para viabilidade da semente. Brasília: Agiplan, 1976. $103 p$

6. Dhingra, O. Prejuízos causados por microrganismos durante o armazenamento de sementes. Revista Brasileira de Sementes, Brasília, v.7, n.1, p.139-146, 1985.

7. Gonçalves, N.P.; Bendezú, J.M.; Lima, C.A.S. Colheita e armazenamento da mamona. Informe Agropecuário, Belo Horizonte, v.82, n.7, p.44-45, 1981.

8. Kennedy, B.W. The occurrence of Aspergillus spp. on stored seeds. Seed pathology, Iapar, p.257-261, 1979.

9. Lopes, J.C.; Jardim, I.C.; Sobreira, D.G.; Forde, G.H.A.; Tatagiba J.S. Associação entre germinação, vigor e sanidade em sementes de milho precoce e normal, produzidos na área experimental do Centro Agropecuário da UFES. Informativo ABRATES, Brasília, v. 1, n.4, 1991, 55p.

10. Marcos Filho, J. Fisiologia de sementes de plantas cultivadas. Piracicaba: Fealq, 2005, 495p.

11. Mariotto, P.R.; Barros, B.C.; Sugimori, M.H.; Menten, J.O.M.; Moraes, S.A.; Savy Filho, A. Efeito do tratamento químico de sementes de mamona (Ricinus communis L.) avaliado por diferentes métodos de patologia de sementes. Arquivos do Instituto Biológico, São Paulo, v.54, n.1/4, p.37-44, 1987.

12. Massola, N.S; Bedendo, I.P. Doenças da mamoneira (Ricinus communis). In: Kimati, H.; Amorim, L.; Rezende, J.A.M.; Bergamim Filho, A.; Camargo, L.E.A. (Ed.). Manual de fitopatologia: doenças das plantas cultivadas. 4. ed. São Paulo: Agronômica Ceres, 2005, v.2, p.497-500.

13. Mazzani, B. Euforbiáceas oleaginosas. Tártago. In: Mazzani, B. Cultivo y mejoramiento de plantas oleaginosas. Caracas: Fondo Nacional de Investigaciones Agropecuarias, 1983, p. 277-360.

14. Moshkin, V.A. Castor. New Delhi: Oxonian Press, 1986. 315p.

15. Nóbrega, F.V.A.; Suassuna, N.D. Análise sanitária de sementes de amendoim (Arachis hypogaea L.) armazenadas em algumas áreas do estado da Paraíba. Revista de Biologia e Ciências da Terra, Campina Grande, v.4, n.2, 2004.

16. Poppinigis, F. Fisiologia da semente. Brasília: AGIPLAN, 1985. 289 p.

17. Savy Filho, A.; Amorim, E.P.; Ramos, N.P.; Martins, A.L.M.; Cavichioli, J.C. IAC-2028: nova cultivar de mamona. Pesquisa Agropecuária Brasileira, Brasília, v.42, n.3, p.449-452, 2007.

18. Savy Filho, A. Mamona: tecnologia agrícola. Campinas: Emopi, 2005. $105 \mathrm{p}$.

19. Silva, R.T.V.; Homechin, M.; Fonseca. E.P.; Santiago, D.C. Tratamento de sementes e armazenamento na sanidade de sementes de paineira (Chorisia specisaSt. Hil). Ciências Agrárias, Londrina, v.24, n.2, p.255-260, 2003.

20. Soave, J.; Moraes, S.A. Medidas de controle das doenças transmitidas por sementes. In: Soave, E.J.; Wetzel, M.M.V.S. (Ed.). Patologia de sementes. 14. ed. Campinas: Fundação Cargill, 1987, p. 192-252.

21. Tanaka, M.A.S. Sobrevivência de Fusarium moniliforme em sementes de milho mantidas em duas condições de armazenamento. Fitopatologia Brasileira, Brasília, v.26, p.60-64, 2001.

22. Vallarini, P.J.; Lasca, C.C.; Vechiato, M.H.; Schidt, J.R.; Dion, P.; Chiba, S. Tratamento de semente de sorgo (Sorghum sp) com fungicidas visando controle de Colletotrichum graminicola e outros fungos associados às sementes. Fitopatologia Brasileira, Brasília, v.3, n.13, p.238-243, 1998.

23. Wetzel, M.M.V.S. Fungos de armazenamento. In: Soave, E.J.; Wetzel, M.M.V.S. (Ed.). Patologia de sementes. Campinas: Fundação Cargill, 1987, p. 562-568.

24. Zonta, E.P.; Machado, A.A. Sistema de análise estatística para microcomputadores: manual de utilização. 2.ed. Pelotas: UFP, 1987. $177 \mathrm{p}$. 